\title{
Performance of solar photovoltaic installations: Effect of seasonal variations
}

\author{
M. Shravanth Vasisht, J. Srinivasan, Sheela K. Ramasesha* \\ Divecha Centre for Climate Change, Indian Institute of Science, Bangalore 560012, India
}

Received 16 September 2015; received in revised form 30 January 2016; accepted 6 February 2016

Communicated by: Associate Editor Bibek Bandyopadhyay

\begin{abstract}
A $20 \mathrm{~kW}_{\mathrm{p}}$ Solar Photovoltaic (SPV) system was set up on the library roof-top in Indian Institute of Science, Bangalore, India. This roof-top photovoltaic (RTPV) system partly powers the Central Office of IISc. The main objective of setting up this SPV system was to study the performance of solar plants under different seasons and climatic conditions of Bangalore. The system has been producing an average daily yield of approximately $80 \mathrm{kWh}$ for the past two years which translates to an annual yield of $28.9 \mathrm{MWh}$. The overall yield of the system up to $14^{\text {th }}$ September 2015 is $70 \mathrm{MWh}$. This work focuses on the evaluation of the performance of SPV systems using the popular grading systems, namely Capacity Utilization Factor (CUF) and Performance Ratio (PR). The CUF of the SPV system is $16.5 \%$, which lies within the range of CUF of well-performing solar plants located in India. Average Performance Ratio (PR) of the SPV system is around $85 \%$, which indicates that the performance of the SPV system is satisfactory. PR of the SPV system is correlated with the behaviour of SPV modules in different seasons, with module temperature $\left(T_{\text {mod }}\right)$ as the key factor of comparison. In summer, the SPV modules attain maximum efficiency $\left(\eta_{\max }\right)$ at $T_{\bmod }$ of $45^{\circ} \mathrm{C}$, but in winter, it is at $55^{\circ} \mathrm{C}$. In summer, for $T_{\bmod }>45^{\circ} \mathrm{C}$, module efficiency $(\eta)$ reduces by $0.08 \%$ per degree rise in temperature. In monsoon, for $T_{\bmod }>35^{\circ} \mathrm{C}, \eta$ reduces by $0.04 \%$ per degree rise in temperature. In post-monsoon period, for $T_{\bmod }>38^{\circ} \mathrm{C}, \eta$ reduces by $0.06 \%$ per degree rise temperature. However, in winters, the modules attain $\eta_{\max }$ at $T_{\bmod }$ of $55^{\circ} \mathrm{C}$, without much drop in efficiency. This is mainly because of intermittent natural cooling that takes places at the surface of the modules, due to cool breeze and lower ambient temperatures.
\end{abstract}

(c) 2016 Elsevier Ltd. All rights reserved.

Keywords: Solar; Renewable; Energy; Power; Efficiency; Module temperature

\section{Introduction}

The performance of a solar photovoltaic system (SPV) is dependent upon many site-specific factors such as latitude, season, cloudiness, and air pollution. Hence, a detailed analysis of the performance of SPV systems will provide valuable information for the prediction of the performance of such systems in the future in order to improve power

\footnotetext{
* Corresponding author. Tel.: +91 802293 3427; fax: +91 8023603425.

E-mail address: sheela@caos.iisc.ernet.in (S.K. Ramasesha).
}

system planning and demand-side management. In 2013, a photovoltaic park with a capacity of $171.36 \mathrm{~kW}_{\mathrm{p}}$ was installed in Sitia, Crete and its performance evaluation showed an annual yield was in the range 335.45$869.68 \mathrm{kWh}$ and the Performance Ratio (PR) was $67.36 \%$ (Kymakis et al., 2008). In 2013-14, a $15 \mathrm{~kW}_{\mathrm{p}}$ gridconnected SPV system located in Mumbai, India was evaluated for economic viability. The monthly production of this SPV system was around $1800 \mathrm{kWh}$, thus saving around 1.6 tonne of $\mathrm{CO}_{2}$ emission into the atmosphere (Shivalkar et al., 2015). A $2 \mathrm{~kW}_{\mathrm{p}}$ grid-connected SPV system located 
in Nis, Republic of Serbia showed that the performance ratio of the system during the period 2013-14 was $93.6 \%$, with a capacity utilization factor of $12.88 \%$ (Mediavilla et al., 2013). Significant findings in the field of power electronic circuits, such as inverters, charge controllers and voltage stabilizers, have contributed for the improvement in the energy conversion systems. For instance, a comparative analysis of DC to AC inverters has shown that transformerless inverters performed better than a conventional system (Milosavljevic et al., 2015). In parallel with the above mentioned findings, there are research activities focussing on maximizing of the existing SPV modules. In 2013, an experiment demonstrating the cooling of SPV modules with temperature controlled solar collector was conducted in Turkey. This mechanism, called a PVT System, uses the heat of the SPV module to cool the PV surface by employing a heat exchanger. The efficiency of the PV modules with cooling was found to be $13 \%$, whereas for the modules without cooling, it was $10 \%$. The PVT system lowers the module temperature by $10-20^{\circ} \mathrm{C}$, which increases the electrical output of the PV system by $5-10 \%$ (Conserval Engineering Inc., 2015). In 2012-13, the study focussing on the influence of ambient temperature and wind-speed on the performance of a monocrystalline SPV system installed in Tripura, India, concluded that ambient temperature ranging between 20 and $38^{\circ} \mathrm{C}$ has a positive correlation with the efficiency of the PV system (Bhattacharya et al., 2014). In 2011, the influence of angle of tilt of PV, albedo of earth, building azimuth and shading effects on power generation of SPV modules were studied to optimize the performance of a Building Integrated Photovoltaic (BIPV) system located in Korea. The efficiency of this BIPV system during different months were compared. According to this study, the power generation is more influenced by the above factors in summer than in winter. This study also concludes that the influence of each of the above factors on the performance of BIPV vary during each season (Yoo, 2011).

The behaviour of SPV systems installed in different locations is a function of the atmospheric and local conditions. Unless a thorough investigation is carried out for the location, it is difficult to predict the performance and energy production capability. It becomes important to carry out field tests and scientific analysis of the data at the location. In this connection, Divecha Centre for Climate Change, Indian Institute of Science (IISc), Bangalore installed a $20 \mathrm{~kW}_{\mathrm{p}}$ grid-interactive SPV system atop J.R.D. Tata Memorial Library (shown in Fig. 1), to study the performance of SPV systems in the city. This SPV system was commissioned in April, 2013 and has been performing optimally to date. This project was partly funded by Ministry of New and Renewable Energy (MNRE) during a drive to power heritage buildings of the country using solar power. The system partially powers the Main Administrative Building of IISc, which is over hundred years old and is identified as a Heritage Site. This building is situated at a distance of around $300 \mathrm{~m}$ from the Library.

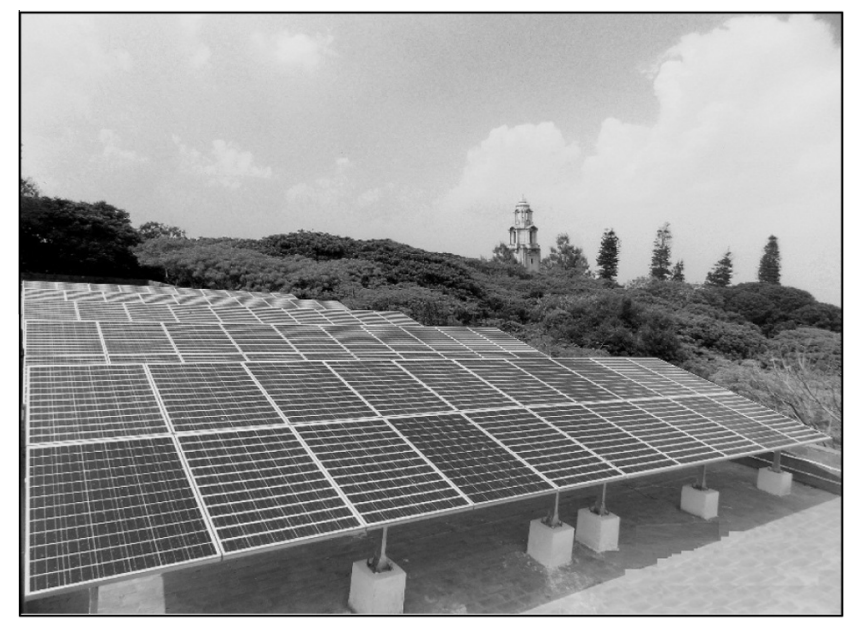

Fig. 1. Ariel view of the $20 \mathrm{~kW}_{\mathrm{p}}$ grid-interactive SPV system.

The SPV modules are oriented towards the south with an inclination of $13^{\circ}$, which is the latitude of the location. The SPV system covers an area of 204 sq. $m$ that includes array to array clearance of $1.5 \mathrm{~m}$. Net PV area of the SPV system is $145 \mathrm{sq}$. $\mathrm{m}$. The system consists of 100 polycrystalline silicon PV modules of $200 \mathrm{~W}_{\mathrm{p}}$ each. Each module consists of 72 cells and each cell has an area of 219.8 sq. mm. In order to achieve optimal system voltage, 20 modules are connected in series to form an array and five such arrays are connected in parallel. The SPV system is mounted on cubical concrete pedestals having edgedimension of $300 \mathrm{~mm}$ each. Since the plant is atop the library building that is 50 years old and houses many rare vintage journals and books, the SPV system had to be installed without tinkering with the rooftop surface to avoid water leakage in the building during monsoon season. The pedestals of approximate weight of $80 \mathrm{~kg}$ have been positioned such that their dead weight exists only on the beams present beneath the floor. One array is mounted on 12 pedestals. The overall weight at the point of contact of each pedestal and the roof is $120 \mathrm{~kg}$. The module mounting structures are made up of galvanized mild steel and are mounted on the concrete pedestals. The structures are designed to withstand a wind velocity of $160 \mathrm{~km} / \mathrm{h}$. The SPV system is being protected by a lightning arrester, super-earth kits and isolator switches to avoid voltage surges.

An array junction box is provided where the output of each array is combined and fed as the input for the Power Conditioning Unit (PCU). A $20 \mathrm{kVA}$ wall-mounted PCU is used in the system. This PCU doesn't employ a transformer and hence, popularly called TL inverters. TL inverters use a computerized multi-step process and electronic components to convert DC to high frequency $\mathrm{AC}$, back to DC, and ultimately to standard-frequency AC. TL PCU has $2 \%$ higher efficiency than the conventional PCU. Additionally, without the transformer, the inverter becomes compact and more affordable. TL inverters use electronic (rather than mechanical) switching, thus reducing the 
amount of heat and 'hum' generated by the unit. The PCU being used consists of two MPPTs (Maximum Power Point Trackers). The main benefit of a PCU consisting of two MPPTs is that it enables the installation to be considered as two different systems. This means that some SPV modules can be placed on a north-facing roof and some on a west-facing roof, without worrying about the lower irradiance on one side dragging the whole system down. In other words, the dual MPP tracker enables the user to install more modules and generate higher energy on a limited roof space (Civic Solar Inc., 2014).

A remote monitoring system called Solar-Log has been installed in the inverter room of the SPV plant which records the real-time data and maintains the database of the previous data. This equipment has the remote access facility and transmits the real-time data to the server. The GHI and power output data are being collected at an intervals of $5 \mathrm{~min}$. The power generation patterns from the SPV system during various seasons corresponding to changes in weather conditions are studied.

\section{Performance analysis of the SPV system}

The performance analysis of an SPV system involves evaluation of various instantaneous parameters that are recorded by the data acquisition system incorporated in the SPV system. The parameters considered in this study are yield, incident solar radiation (Global Horizontal Irradiance - GHI), module temperature and ambient temperature. These parameters are measured from dawn to dusk.
However, the effective period of generation (EPG) is the period during which the instantaneous power output is at least $25 \%$ of the installed capacity, which is in the period 08:00-16:00 h.

The monthly yield, $Y_{\text {net (m) }}$ of the SPV system during the study period considered is shown Fig. 2. The highest $Y_{\text {net (m) }}$ of the study period was in March 2014 with $3132 \mathrm{kWh}$ and least was in July with $1579 \mathrm{kWh}$, corresponding to summer and monsoon months. The highest and lowest daily yields of the SPV system in the period considered was $120 \mathrm{kWh}$ and $40 \mathrm{kWh}$, respectively, with corresponding specific yields, $S_{\text {day }}$ of $6 \mathrm{kWh} / \mathrm{kW}_{\mathrm{p}}$ and $2.0 \mathrm{kWh} / \mathrm{kW}_{\mathrm{p}}$, respectively. The net annual yield, $Y_{\text {net (annual) }}$ during this period was $28.9 \mathrm{MWh}$ with an annual average daily specific yield,

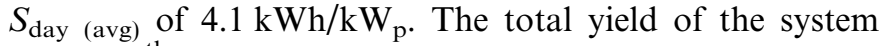
up to $14^{\text {th }}$ September, 2015 is $70 \mathrm{MWh}$ and the annual average daily yield over the study period is $83 \mathrm{kWh}$. Since coal is the major source of electricity in India, installation of the SPV system has avoided at least 23 tonnes of carbon di-oxide $\left(\mathrm{CO}_{2}\right)$ emission into the atmosphere per year (taking the amount of $\mathrm{CO}_{2}$ emission as $800 \mathrm{~g}$ per $\mathrm{kWh}$ of electricity production from coal fired thermal plants) (International Energy Agency, 2013) because the Main Administrative Building of IISc has drawn that much less power from the grid.

The trend of monthly average daily sunshine period (EPG), $t_{\mathrm{s}}$, is shown in Fig. 2. During the months July and August, the sunshine period was lower due to southwest monsoon over Indian subcontinent, which reflected on the $Y_{\text {day }}$ of the PV system. Fig. 3 represents the

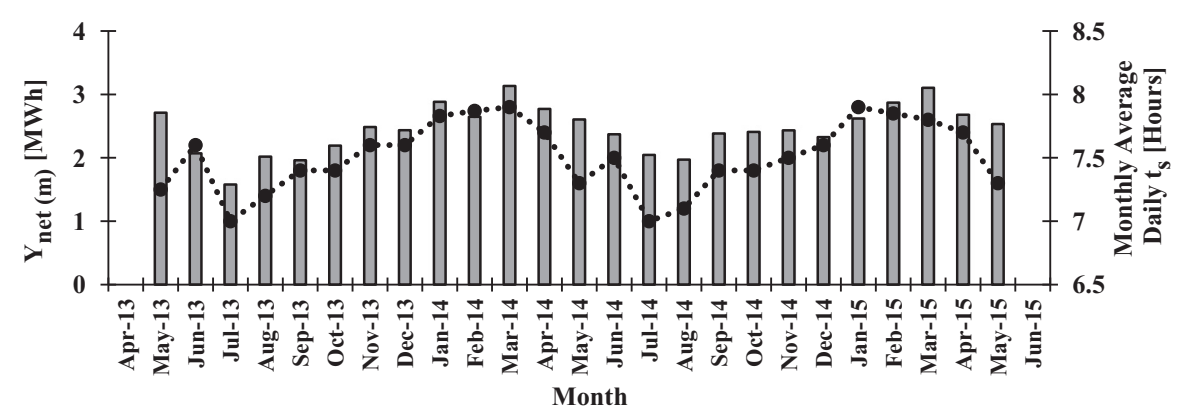

Fig. 2. Variation of monthly yield, $Y_{\text {net (m) }}$ corresponding to average daily sunshine period, $t_{\mathrm{s}}$, during the period 2013-15. The bars denote monthly yield and circles denote monthly average daily sunshine period.

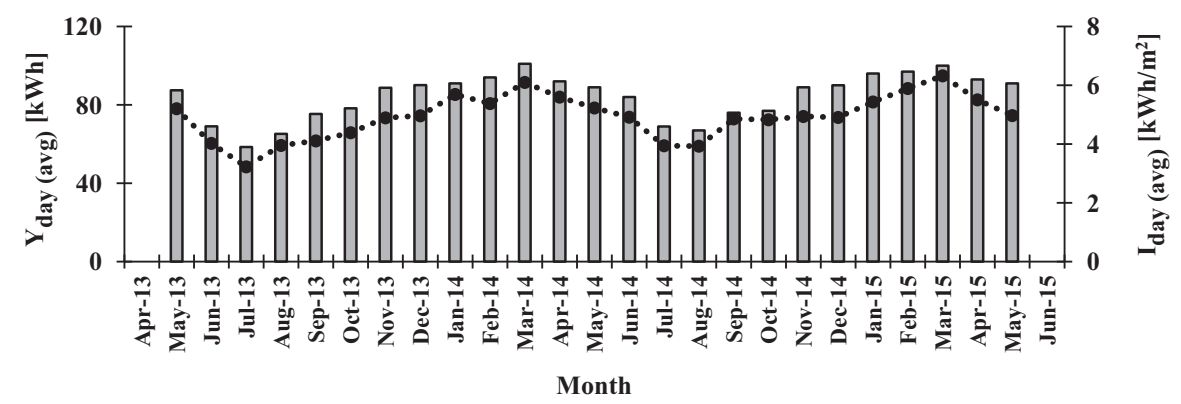

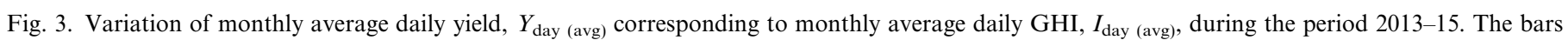
denote monthly average daily yield and circles denote monthly average daily GHI. 


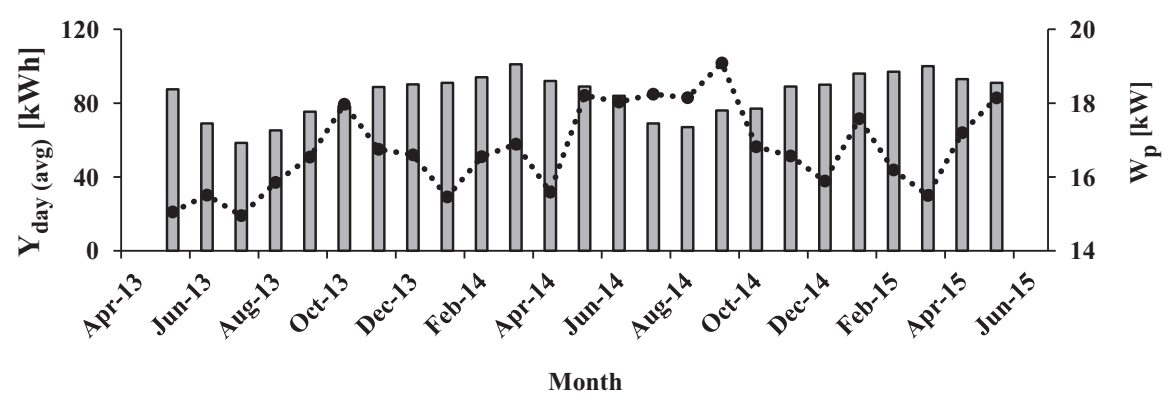

Fig. 4. Variation of monthly average daily yield, $Y_{\text {day (avg) }}$ corresponding to peak power of the month, $W_{\mathrm{p}}$, during the period 2013-15. The bars represent monthly average daily generation and circles represent peak power of the month.

variation in the monthly average $Y_{\text {day }}$ corresponding to monthly average $I_{\text {day }}$.

Fig. 4 represents the variation of $Y_{\text {day }}$ with peak power, $W_{\mathrm{p}}$. It is clear from Fig. 4 that the daily GHI, $I_{\text {(day) }}$ was high during the summer months - January, February, March and April. The highest peak power of the study period attained was on $12^{\text {th }}$ October, 2013, rising up to $19.9 \mathrm{~kW}$. On this day, the PCU exhibited an efficiency of $1.4 \%$ higher than the rated efficiency. The average peak power of this month was $17.97 \mathrm{~kW}$. However, the instantaneous peak power rising up to $99 \%$ of installed capacity cannot be taken into account while judging the performance of the SPV system and hence could be misleading.

\subsection{Grading of the SPV System}

The yield of the SPV system which is the most important metric of an SPV system is directly related to the following system-level metrics (Chakraborty et al., 2015):

- Capacity Utilization Factor (CUF).

- Performance Ratio (PR).

SPV systems are graded based on these system-level metrics. These metrics are a function of both atmospheric and electrical parameters. The grading indices of the above mentioned factors are totally different from each other as each of these factors account for a wide range of parameters. Detailed analysis of these factors are discussed in the following sections.

\subsubsection{Capacity utilization factor}

The Capacity Utilization Factor (CUF) of the SPV system is the ratio of actual energy generated by the SPV system to the equivalent energy output from a similar system that works $24 \mathrm{~h}$ a day (Re-solve, 2014). CUF of the SPV system is calculated as shown below:

$$
\begin{aligned}
\text { CUF } & =\frac{\text { Annual yield }}{20 \mathrm{~kW} \times 24 \mathrm{~h} \times 365 \text { days }} \times 100 \\
& =\frac{28,882 \mathrm{kWh}}{20 \mathrm{~kW} \times 24 \mathrm{~h} \times 365} \times 100=16.5 \%
\end{aligned}
$$

CUF of the SPV system is $16.5 \%$ and is well within the range of average CUF of all the roof top SPV systems in India, which is $16-17 \%$ (Bridge to India, 2015). CUF is dependent on the location. For example, the average CUF of SPV system located in Arizona, USA is $19 \%$, whereas in Massachusetts, USA, it is $13-15 \%$ (Academia, 2015). The CUF of the system is mainly dependent on the GHI at the location of the SPV system and the cell efficiency of the SPV modules.

\subsubsection{Performance ratio}

One of the most important variables for evaluating the performance of a SPV system is the Performance Ratio (PR). Specifically, PR is the ratio of the actual yield and theoretically calculated yield. PR is expressed as a percentage and remains as a factor of comparison of all PV systems installed in different locations of the world. As PR is measure of the quality of a PV system independent of its location, PR is often called 'Quality Factor'. PR illustrates the proportion of the energy that is actually available for export to the grid after deduction of energy loss and energy consumption for operation. The energy losses also include thermal losses and conductor losses. The closer the PR value determined for a PV system approaches $100 \%$, the more efficient is its operation. However, $100 \%$ PR cannot be achieved in ideal case as unavoidable losses always arise with the operation of the PV system. Highperformance $\mathrm{PV}$ systems can however reach a performance ratio of up to $80 \%$ (Verma and Singhal, 2015). PR can be calculated using the following equation:

$$
\mathrm{PR}=\frac{\text { Actual yield }(\text { in } \mathrm{kWh})}{\text { Calculated nominal yield }}
$$

where

$$
\begin{aligned}
\text { Calculated nominal yield }= & \text { GHI }\left(\text { in } \mathrm{kWh} / \mathrm{m}^{2}\right) \\
& \times \text { Rated module efficiency } \\
& \times \text { Total PV area }\left(\text { in } \mathrm{m}^{2}\right)
\end{aligned}
$$

As an example, PR is calculated for October 17, 2013. Measured GHI in the day, $I_{\text {day }}: 5.496 \mathrm{kWh} / \mathrm{m}^{2}$. 
Rated module efficiency, $\eta_{\text {rated }}=\eta_{\mathrm{STC}}=13.71 \%$. Daily yield, $Y_{\text {day }}: 100 \mathrm{kWh}$.

Thus, an anticipated nominal yield is $109.25 \mathrm{kWh}$. This anticipated nominal yield corresponds to a performance ratio of $100 \%$. However, the actual energy exported by the PV system to the grid is only $100 \mathrm{kWh}$. If this value and the calculated nominal plant output are fed into the formula for calculating the performance ratio, the following result is obtained:

$\mathrm{PR}=\frac{100 \mathrm{kWh}}{109.25 \mathrm{kWh}} \times 100=91.5$

Hence, PR value of the day is $91.5 \%$. This means that $8.5 \%$ of the incident solar energy is not converted into usable energy due to circumstances such as conduction loss, thermal loss or defects in components. Here, PR acts as an indicator and can prompt more detailed inspection of the PV system, so that the faults and losses can be avoided or debugged.

The performance of an SPV system is dependent on the actual AC energy output in a definite period of time, relative to the expected DC output. The expected output can either be based on ideal solar insolation or actual solar insolation, yielding two different metrics. CUF compares the output of the SPV system to the output of an ideal (lossless) system with identical nameplate capacity operating at STC (AM 1.5, GHI $1000 \mathrm{~W} / \mathrm{m}^{2}, T_{\text {amb }} 25^{\circ} \mathrm{C}$ ). Whereas PR compares the system output to that of an ideal system operating at $25^{\circ} \mathrm{C}$ in the same location (under same solar insolation). Also, solar power is available only during daylight hours. Hence, CUF is limited to the fraction of daylight hours. By accounting for geographical and temporal variations in solar insolation, PR isolates non-ideal module and system losses due to elevated temperatures or component failures and allows comparison of PV systems in different locations (Jean et al., 2015). Thus, PR defines the performance of an SPV system rather than CUF.

Fig. 5 shows the variation in performance ratio during the study period. Fig. 5(a) and (b) shows the variation in monthly average daily $\mathrm{PR}$ value, $\mathrm{PR}_{\mathrm{avg}}$, with respect to monthly average daily yield, $Y_{\text {day (avg) }}$ and monthly average module temperature, $T_{\text {mod }}$. As seen from Fig. 5(a), the $\mathrm{PR}_{\text {avg }}$ of the SPV system is comparatively lower for the months March, April, May, November and December than the other months of the year. From Fig 5(b), it is clear that there is an inverse relationship between $\mathrm{PR}_{\text {avg }}$ and $\mathrm{T}_{\text {mod. }}$. For better understanding, the study period is divided into four seasons, namely June-August (monsoon), September-November (post-monsoon), December-January (winter) and February-May (summer). Fig. 5(c) shows the variation in performance ratio of each season. The gradient in maximum and minimum $P R$ values with reference to the average value of each season are different. For example, in monsoon, $\mathrm{PR}_{\text {avg }}, \mathrm{PR}_{\max }$ and $\mathrm{PR}_{\min }$ are $87.3 \%, 89.3 \%$ and $79.8 \%$ respectively. In post-monsoon period, $\mathrm{PR}_{\mathrm{avg}}, \mathrm{PR}_{\max }$ and $\mathrm{PR}_{\min }$ are $85.6 \%, 95.0 \%$ and $77.7 \%$ respectively. The gradient in $\mathrm{PR}_{\mathrm{avg}}$ with $\mathrm{PR}_{\max }$ and $\mathrm{PR}_{\min }$ values of postmonsoon period is larger than monsoon period. The gradient pattern in winter is also similar to post-monsoon whereas in summer, the gradient in $\mathrm{PR}_{\max }$ and $\mathrm{PR}_{\min }$ is highest. This indicates that the performance of the SPV system is dependent on the atmospheric parameters, which are different in various seasons. One of the prominent parameters that varies during the four seasons is the ambient temperature, which is a function of incoming solar radiation.

Delivering $100 \%$ of the rated power of a SPV module is possible if solar radiation is the only factor affecting the performance of the module. However, the major factor which does not allow the solar cells to showcase best performance is the module temperature, $T_{\bmod }$ (Huld and Amillo, 2015), which is a function of ambient temperature. The SPV module undergoes heating on its exposure to the sunlight and the temperature measured at the surface of the module is directly proportional to the incident solar radiation. It is calculated that module temperature is around 1.5 times higher than ambient temperature. This proportionality is applicable only when physical parameters such as wind, rain and breeze do not exist.

The ratio of output power of the SPV module by input power, which is the incident solar radiation is defined as module efficiency, $\eta$ and is given by,

Efficiency, $\eta=\frac{\text { Power output }}{\text { Power input }} \times 100$

where power input, $P_{\text {in }}$ is a product of incident solar radiation flux $\left(I_{\mathrm{i}}\right)$ in W/m $/ \mathrm{m}^{2}$ and total $\mathrm{PV}$ area. Power output, $P_{\text {out }}=V_{\mathrm{oc}} \times I_{\mathrm{sc}} \times \mathrm{FF}$ with FF being the fill factor. The power output of a module is dependent on $V_{\text {oc }}$ and $I_{\text {sc }}$. $V_{\mathrm{oc}}$ is the maximum voltage measured across the terminals of the module or cell when current is 0 . The effect of $T_{\text {mod }}$ on $V_{\mathrm{oc}}$ and $I_{\mathrm{sc}}$ are different. $V_{\mathrm{oc}}$ of the cell linearly decreases with increase in $T_{\text {mod }}$. On the other hand, the effect of $T_{\text {mod }}$ on $I_{\mathrm{sc}}$ (quantified as temperature coefficient of $I_{\mathrm{sc}}, \alpha$ ) is comparatively smaller than the effect on $V_{\text {oc }}$ and is around $0.6 \mathrm{~mA}$ per ${ }^{\circ} \mathrm{C}$ for silicon (PV Education, 2014). Thus, one of the factors which majorly hampers $\eta_{\mathrm{i}}$ at higher temperatures is $V_{\mathrm{oc}}$. The impact of $T_{\text {mod }}$ on $V_{\mathrm{oc}}$ is denoted as temperature coefficient of $V_{\mathrm{oc}}, \beta$ and is calculated using Eq. (5).

Temperature coefficient of $V_{\mathrm{oc}}, \beta=\frac{d V_{\mathrm{oc}}}{d T}$

$$
=-\frac{V_{\mathrm{GO}}-V_{\mathrm{oc}}+\gamma \frac{k T}{q}}{T}
$$

where $V_{\mathrm{GO}}$ is the zero temperature band gap voltage of silicon, $\gamma=3$ and $q$ is the electron charge, $k T$ is thermal energy, which is the product of Boltzmann constant, $k$ and temperature at STC, $T_{\mathrm{STC}}$. The drop in $V_{\mathrm{oc}}$ per ${ }^{\circ} \mathrm{C}$ is found to be $2.06 \mathrm{mV}$ for the SPV cells under consideration, which lies within the range of $\beta$ values of polycrystalline solar cells (Bensalem et al., 2013).

For one of the hottest days of the study period $\left(31^{\text {st }}\right.$ March, $2014)$, at $I_{\mathrm{i}}=881 \mathrm{~W} / \mathrm{m}^{2} ; T_{\bmod }=T_{\bmod (\max )}=63^{\circ} \mathrm{C}$, the efficiency, $\eta_{\mathrm{i}}(\mathrm{T})$ is calculated as $12.08 \%$. Whereas, for a 

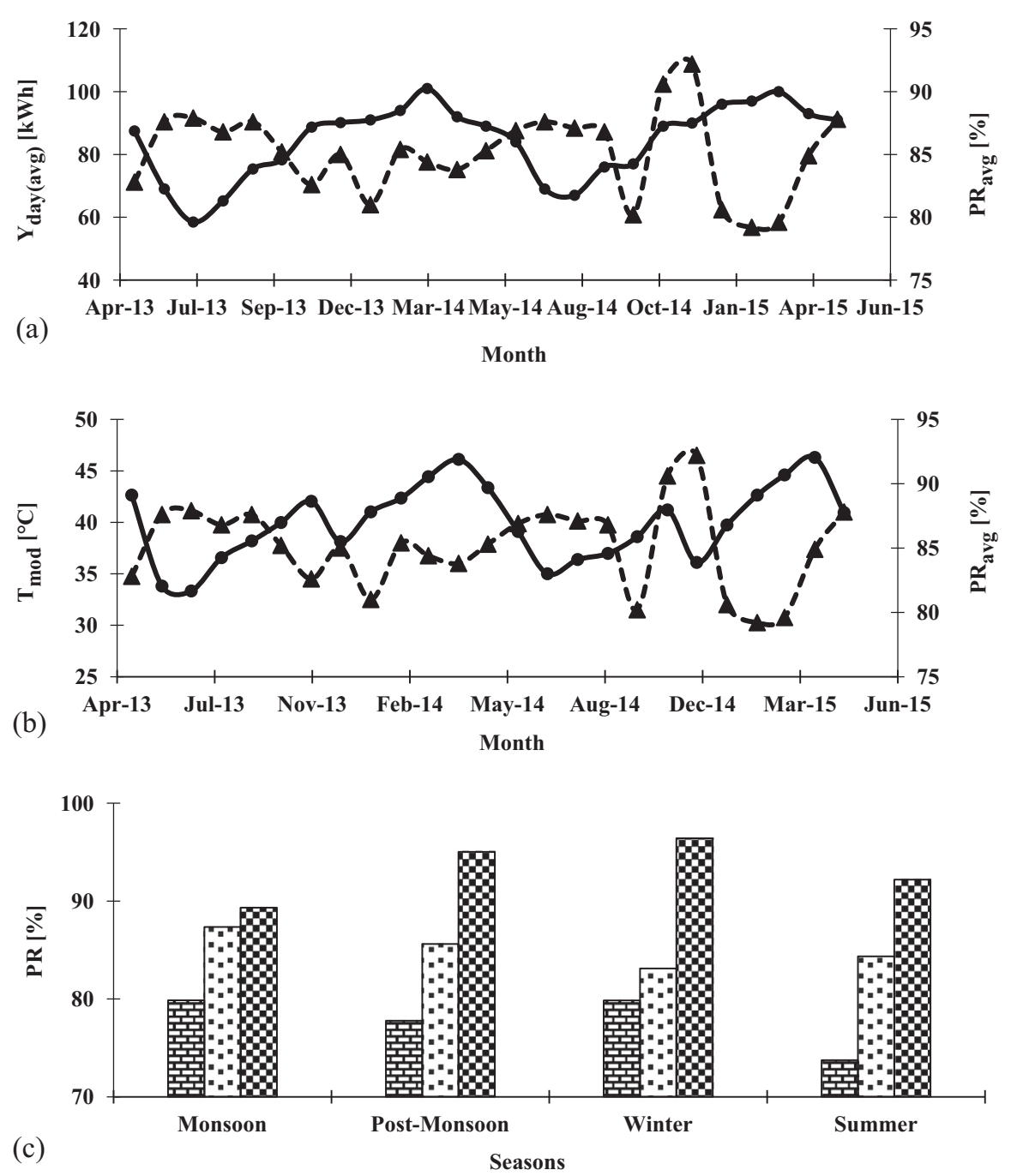

Fig. 5. Variation in performance ratio, $P R$ in different months of the study period. (a) Variation in monthly average daily performance ratio, $P R_{a v g}$ corresponding to monthly average daily yield, $Y_{\text {day (avg). }}$ The circles represent $Y_{\text {day (avg) }}$ and triangles represent $P R_{\text {avg. }}$ (b) Variation in monthly average daily performance ratio, $\mathrm{PR}_{\text {avg }}$ corresponding to monthly average module temperature, $T_{\text {mod. }}$ The circles represent $T_{\text {mod }}$ and triangles represent $P R_{\text {avg. }}$ (c) Variation in seasonal average daily $\mathrm{PR}\left(\mathrm{PR}_{\mathrm{avg}}\right)$, seasonal maximum $\mathrm{PR}\left(\mathrm{PR}_{\max }\right)$ and seasonal minimum $\mathrm{PR}\left(\mathrm{PR}_{\min }\right)$ in different seasons. Brick bars represent $P R_{\text {min }}$, dotted bars represent $P R_{\text {avg }}$ and checker bars represent $P_{\max }$.

day with moderate weather $\left(18^{\text {th }}\right.$ June, 2013), at $I_{\mathrm{i}}=841 \mathrm{~W} / \mathrm{m}^{2} ; \quad T_{\text {mod }}=T_{\text {mod }} \quad(\max )=46^{\circ} \mathrm{C}, \quad \eta_{\mathrm{i}} \quad$ (T) is $13.01 \%$. It is clear that $\eta_{\mathrm{i}\left(63^{\circ} \mathrm{C}\right)}<\eta_{\mathrm{i}\left(46^{\circ} \mathrm{C}\right)}<\eta_{\mathrm{i}(\mathrm{STC})}$, which is mainly due to decrease in $V_{\mathrm{oc}}$ at higher $T_{\text {mod }}$ (Radziemska, 2003).

However, the variation in the module efficiencies of clear days of different seasons are different. Module temperatures, $T_{\text {mod }}$ attained by the SPV modules in different seasons of the study period is one of the key reasons for varying patterns of $\eta$, thereby affecting performance ratio. The gradient in $I_{\mathrm{i}}$ is dissimilar for different seasons of the study period and so are the corresponding module temperatures. For better understanding, the seasonal average of $\eta_{\mathrm{i}}$ and $I_{\mathrm{i}}$ for $T_{\text {mod }}>T_{\text {mod (M) }}$ are calculated and plotted as shown in Fig. 6. The unique variation in the performance of the SPV system during the four seasons are discussed below.

\subsection{Summer}

It is seen that the highest module efficiency, $\eta_{\max }$ during summer is $13.28 \%$ at $T_{\text {mod }}$ of $45^{\circ} \mathrm{C}$, which is $96.8 \%$ of $\eta_{\text {rated. }}$ For $T_{\text {mod }}>T_{\text {mod (M) }}\left(T_{\text {mod }}\right.$ at $\left.\eta_{\text {max }}\right), \eta_{\mathrm{i}}$ reduces by $0.085 \%$ per degree rise in $T_{\text {mod }}$. In peak summer months, $T_{\text {mod }}$ and $T_{\mathrm{amb}}$ are quite high, thus leading to low PR values. $\mathrm{PR}_{\text {avg }}$ value during summer months is $83.7 \%$, which is significantly lower compared to monsoon and postmonsoon, but higher than winter. $\mathrm{PR}_{\max }$ value is comparatively less than that of post-monsoon and winter.

\subsection{Monsoon}

$T_{\text {mod }}$ during the monsoon period are in the range of $21^{\circ} \mathrm{C}$ and $56^{\circ} \mathrm{C}$, with $\eta_{\max }$ of $13.18 \%$ at $T_{\bmod }$ (M) of $39{ }^{\circ} \mathrm{C}$, which is $96.13 \%$ of $\eta_{\text {rated }}$. The average rate of rise 


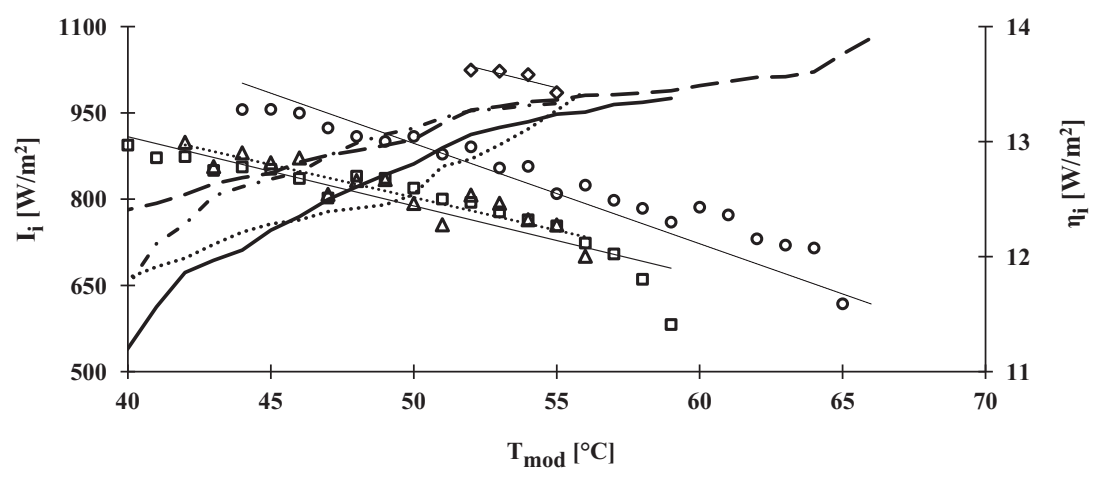

Fig. 6. Variation of module efficiency, $\eta_{\mathrm{i}}$ and GHI, $I_{\mathrm{i}}$ in different seasons as a function of module temperature, $T_{\text {mod }}$. Circles, triangles, squares and rhombuses represent $\eta_{\mathrm{i}}$ during summer, monsoon, post-monsoon and winter, respectively. Bold lines denote $I_{\mathrm{i}}$ and normal lines denote trend line for $\eta_{\mathrm{i}}$. Broken lines, dotted lines, solid lines and dash-dotted lines represent summer, monsoon, post-monsoon and winter, respectively.

in $T_{\text {mod }}$ in the months of south-west monsoon is much low compared to summer, mainly due to partly cloudy weather. Hence, $\eta_{\max }$ is achieved at comparatively lower values of $T_{\text {mod }}$ than the other months of the year. For $T_{\text {mod }}>T_{\text {mod }(\mathrm{M})}, \eta_{\mathrm{i}}$ reduces by $0.044 \%$ per degree rise in $T_{\text {mod. }} \mathrm{PR}_{\text {avg }}$ value of this period is $87.3 \% . \mathrm{PR}_{\text {avg }}$ value of this season is quite high compared to $\mathrm{PR}_{\mathrm{avg}}$ of other seasons, though $Y_{\text {day }}$ is lower than other seasons. This is mainly because $T_{\text {amb }}$ and $T_{\text {mod }}$ values are lower than that of summer and post-monsoon period, though not as low as winter.

\subsection{Post-monsoon}

The range of $T_{\text {mod }}$ during post-monsoon period is similar to the monsoon. At $T_{\bmod (\mathrm{M})}$ of $38^{\circ} \mathrm{C}, \eta_{\max }$ is $13.15 \%$, which is $95.91 \%$ of $\eta_{\text {rated }}$. The rate of rise in $T_{\text {mod }}$ during this period is higher than monsoon, thus reducing $\eta_{\mathrm{i}}$ by $0.061 \%$ per degree rise in $T_{\text {mod. }}$. In this period, the sky is clear due to the rainfall of monsoon. $\mathrm{PR}_{\mathrm{avg}}$ value of this period is $85.6 \%$, which is lesser than monsoon, but greater than summer and winter. In this season, random variation in $\mathrm{PR}_{\mathrm{day}}$ is observed due to erratic variation in $T_{\mathrm{amb}}$ and $T_{\text {mod}}$.

\subsection{Winter}

Best performance of the system is observed during winter. $\eta_{\max }$ during this period is $13.62 \%$ at $T_{\bmod (\mathrm{M})}$ of $55^{\circ} \mathrm{C}$, which is $99.34 \%$ of $\eta_{\text {rated }}$. This is mainly due to the intermittent cooling that takes place at the module surface due to the cold winds and lower values of $T_{\mathrm{amb}}$, without allowing the surface of module to reach high temperatures as in summers. Hence, the values of $T_{\bmod }(\mathrm{M})$ during this period is comparatively lower than other seasons. $\mathrm{PR}_{\text {avg }}$ value during winter months is $83.1 \%$, which is lower than monsoon and post-monsoon but higher than summer. However, $\mathrm{PR}_{\max }$ value is highest in winter is the highest among the $\mathrm{PR}_{\max }$ values of other seasons, though the $I_{\text {day }}$ and $t_{\mathrm{s}}$ are lower. This indicates that $T_{\bmod }$ and $T_{\mathrm{amb}}$ majorly influence PR.

\section{Conclusion}

The performance of the $20 \mathrm{~kW}_{\mathrm{p}}$ grid-interactive SPV system is studied and the variation of the daily and monthly yields during the study period is analysed. The annual yield of the system is around 28.9 MWh. Performance evaluation of the SPV system is carried out using the popular grading systems - CUF and PR. The CUF of the SPV system is $16.5 \%$, which lies within the range of CUF of well-performing solar plants located in India. Average PR of the SPV system is around $85 \%$ indicating that performance of the SPV system is at par with the solar plants showcasing good performance.

$T_{\text {mod }}$ plays a key role in the energy output of the system. The annual average $T_{\bmod (\mathrm{M})}$ is calculated as $45^{\circ} \mathrm{C}$. However, $\eta_{\mathrm{i}}$ is attained at different $T_{\text {mod }}$ for the four seasons considered. In summer, $T_{\bmod }(\mathrm{M})$ is $45^{\circ} \mathrm{C}$, but in winter, it is $55^{\circ} \mathrm{C}$. It is also observed that $\eta$ is comparatively low in summer and post-monsoon months though the average $Y_{\text {day }}$ were high, mainly due long sunshine period and high GHI. In summer, for $T_{\text {mod }}>45^{\circ} \mathrm{C}, \eta_{\mathrm{i}}$ decreases by $0.08 \%$ per degree rise in $T_{\text {mod }}$. In monsoon, for $T_{\bmod }>35^{\circ} \mathrm{C}, \eta_{\mathrm{i}}$ reduces by $0.04 \%$ per degree rise in $T_{\text {mod. }}$. In postmonsoon period, for $T_{\text {mod }}>38^{\circ} \mathrm{C}, \eta_{\mathrm{i}}$ reduces by $0.06 \%$ per degree rise in $T_{\text {mod }}$. However, in winters, $T_{\bmod (\mathrm{M})}$ is $55^{\circ} \mathrm{C}$ and doesn't exhibit much drop in $\eta_{\mathrm{i}}$. This is because of intermittent natural cooling that takes places at the surface of the modules due to cool breeze and low ambient temperatures.

It is clear from the study that $\mathrm{PR}_{\mathrm{avg}}$ is inversely proportional to $T_{\text {mod. }}$ Values of $\mathrm{PR}_{\max }$ are higher in winter and post-monsoon than summer and monsoon. This is mainly because of lower $T_{\bmod }$ and $T_{\mathrm{amb}}$ in winter and high GHI in post-monsoon. However, $\mathrm{PR}_{\mathrm{avg}}$ in monsoon and postmonsoon period are higher than winter and summer. This is because of intermittent rainfall during monsoon, which maintain module surfaces at low temperatures and higher number of clear days in post-monsoon period. It is inferred from this study that the major factors influencing the performance ratio of any SPV system is the module efficiency 
and one of the major factor affecting module efficiency is module temperature. Hence, to reap maximum benefit from roof-top SPV installations, it is very essential to maintain the surface of the modules at low temperatures, especially during summers and similar weather conditions of the year.

\section{References}

Academia, 2015. Treehugger, Energy Basics. $<$ https://www.academia.edu/ 8361186/Energy_basics $>$ (last accessed 09.13.15).

Bensalem, S., Chegaar, M., Aillerie, M., 2013. Solar cells electrical behaviour under thermal gradient. In: TerraGreen 13 International Conference 2013 - Advancements in Renewable Energy and Clean Environment, Beirut, Lebanon, February, Energy Procedia, vol. 36, pp. 1249-1254.

Bhattacharya, T., Chakraborty, A.K., Pal, K., 2014. Effects of ambient temperature and wind speed on performance of monocrystalline solar photovoltaic module in Tripura, India. J. Sol. Energy, 1-5.

Bridge to India, 2015. Rooftop revolution: Unleashing Delhi's solar potential, New Delhi: Bridge to India. <http://www.bridgetoindia.com/blog/rooftop-revolution-unleashing-delhis-solar-potential/> (last accessed 05.03.13).

Chakraborty, S., Sadhu, P.K., Pal, N., 2015. Technical mapping of solar PV for ISM-an approach toward green campus. Energy Sci. Eng. 3 (3), 196-206.

Civic Solar Inc., 2014. Transformerless Inverters for Solar PV. $<$ http:// www.civicsolar.com/resource/transformerless-inverters-solar-pv $>$ (last accessed 09.03.14).

Conserval Engineering Inc., 2015. Solar Power Wall. $<$ http://solarwall.com/en/products/pvthermal.php> (last accessed 09.16.15).

Huld, T., Amillo, A.M.G., 2015. Estimating PV module performance over large geographical regions: the role of irradiance, air temperature. Wind Speed Sol. Spectrum. Energies 8 (6), 5159-5181.
International Energy Agency, 2013. Technology Roadmap, High-Efficiency, Low-Emissions Coal-Fired Power Generation. <http://www. iea.org/publications/freepublications/publication/TechnologyRoadmap HighEfficiencyLowEmissionsCoalFiredPowerGeneration_WEB_ Updated_March2013.pdf $>$ (last accessed 09.17.14).

Jean, J., Brown, P.R., Jaffe, R.L., Buonassisi, T., Bulovic, V., 2015. Pathways for solar photovoltaics. Energy Environ. Sci. 8, 1200-1219.

Kymakis, K., Kalykakis, S., Papazoglou, T.M., 2008. Performance analysis of a grid connected Photovoltaic Park on the island of Crete. Energy Convers. Manage. 50, 433-438.

Mediavilla, M.D., Velasco, M.I.D., Amigo, M.C.R., Calderon, T.G., Tristan, C.A., 2013. Performance of grid-tied PV facilities: a case study based on real data. Energy Convers. Manage. 76, 893-898.

Milosavljevic, D.D., Pavlovic, T.M., Pirsl, D.S., 2015. Performance analysis of a grid-connected solar PV plant in Nis, Republic of Serbia. Renew. Sustain. Energy Rev. 44, 423-435.

PV Education, 2014. Nominal Operating Cell Temperature. <http:// pveducation.org/pvcdrom/modules/nominal-operating-cell-temperature $>$ (last accessed 12.05.14).

Radziemska, E., 2003. The effect of temperature on the power drop in crystalline silicon solar cells. Renew. Energy 28 (1), 1-12.

Re-solve, 2014. Solar PV plant performance - Capacity utilization Factor (CUF) vs Performance Ratio (PR). <http://www.re-solve.in/perspectives-and-insights/solar-pv-plant-performance-capacity-utilisation-factorcuf-vs-performance-ratiopr/> (last accessed 09.26.14).

Shivalkar, R.S., Jadhav, H.R., Deo, P., 2015. Feasibility study for the net metering implementation in rooftop solar PV installations across reliance energy consumers. IEEE International Conference on Circuit. Power and Computing Technologies, Nagercoil, India, pp. 1-6.

Verma, A., Singhal, S., 2015. Solar PV performance parameter and recommendation for optimization of performance in large scale grid connected solar PV plant - case study. J. Energy Power Sour. 2 (1), 40 53.

Yoo, S.H., 2011. Simulation for an optimal application of BIPV through parameter variation. Solar Energy 85 (7), 1291-1301. 